(discontinued 1998), Annual Book of Standards, American Society for Testing and Materials, Philadelphia, PA.

25) Clayton, C. R. I. (1990): SPT energy transmission: theory, measurement and significance, Ground Engineering, December, $35-43$.

26) Daniel, C. R., Jackson, R. S., Howie, J. A. and Walker, B. W. (2003): Development of a spreadsheet for modelling SPT stress wave data, Geotech. Test. J., 26(3).

27) Fairhurst, C. (1961): Wave mechanics of percussive drilling, Mine \& Quarry Engineering, Mar., 1961, 122-130, Apr., 1961, 169-178, July, 1961, 327-328.

28) GRL (1997): GRLWEAP-Wave Equation Analysis of Pile Driving-User's Manual, Goble, Rausche, Likins and Associates, Cleveland, Ohio.

29) ISSMFE (1988): Standard Penetration test (SPT): International reference test procedure, Technical Committee on Penetration Testing-SPT Working Party. Proc. 1st Int. Sym. Penetration Testing, Orlando, Fla., March 3-26.

30) Schmertmann, J. H. and Palacios, A. (1979): Energy dynamics of SPT, J. Geotech. Engrg. Div., ASCE, 105(GT8), 909-926.

31) Sy, A. and Campanella, R. G. (1991): An alternative method of measuring SPT energy, Proc. 2nd Int. Conf. Recent Advances in Geotechnical Earthquake Engineering and Soil Dynamics, St. Louis, Mo., 499-505.

32) Sy, A. and Campanella, R. G. (1993): Standard penetration test energy measurements using a system based on the personal computer: Discussion, Can. Geotech. J., 30, 876-882.

\section{EFFECT OF HAMMER SHAPE ON ENERGY TRANSFER MEASUREMENT IN THE STANDARD PENETRATION TEST ${ }^{\mathrm{i})}$}

\author{
Closure by JIIN-Song TSAI ${ }^{\mathrm{ii})}$
}

\section{WHAT IS THE ISSUE?}

The entitled paper is to give an answer to the question: "Do different hammers give the same $N$-values in the Standard Penetration Testing (SPT)?" Those shown experiments and results contribute a laboratory testing view to the long controversy of the hammer-shape effects, excluding many other factors. The discussants dispute the correctness of employing the $F^{2}$ method to calculate the transferred energy, a measurable index showing the hammer-shape effects. Their point brings an important issue regarding the reliability of the chosen research process. To clarify the issue, maybe we should ask the following question:

"Would the concluding answer be different if the $F V$ method instead of the $F^{2}$ method were employed?"

The answer shall remain the same as explained below.

\section{WHAT IS ABOUT THE ENERGY TRANSFER IN OUR LABORATORY TESTING?}

Questioning the lack of velocity measurements, the discussants seriously challenge the correctness of the published rod energy computed using the $F^{2}$ method which measures the force only. According to their analysis, they argue the excellent agreement of the measured $F^{2}$ energy at different locations of the rod published in the paper "was merely a coincidence". Nevertheless, the FVCALC data (58\% obtained using the $F V$ method) shown in Fig. 5(c) in their discussion gives a good agreement to the computed Hammer B result $(59.5 \%$ obtained using the $F^{2}$ method) listed in Table 2 in the paper. Is this another surprising coincidence? The following discussion is to answer "How do all the "coincidences" happen"?

In brief, the discussants' main doubt is about the specific impedance of the interface, i.e. the anvil, between the hammer and the rod. The impedance, or the contact, problem has been long a challenging topic of impact mechanics (Goldsmith, 1959). Some previous experiences, e.g. Farrar (1998), indicate that the anvil acts as an energy trap because the reflected wave is generated in the anvil due to the sectional change of the anvil/rod interface. Their thoughts give a good explanation, and some people have taken for granted the energy loss in the anvil at hammer strike, especially for large drill rods with large anvils. The discussants also assume the anvil energy loss in our experiments is inevitable, and the excellent agreement between the published $\boldsymbol{F}^{2}$ energies for the locations above the anvil and on the rod is then inferred merely as "coincidence".

They would be correct if a special function of the force transducer atop the anvil were ignored. In the laboratory testing, a neatly designed round-top cap (shown in Fig. 5 of the paper) covers the force transducer, which fulfills our need to ease the wave reflection in the anvil to a much lower level than those previous experiences. The function of the round-top cap is to transfer the plane-impact into a point-impact between the hammer and the anvil at pounding (Tsai and Liou, 2001). The cap centralizes the hammer strike onto the anvil and transfers the force to the rod without the interference of sectional change. This innovation effectively avoids the troublesome interface impedance problem and generates a nearly perfect impact at hammer pounding with negligible energy loss.

The key idea is originated from a clever device, the commonly seen Newton's cradle (Fig. 21). The Newton's cradle not only demonstrates a pendulum, but also shows the law of conservation of momentum and energy. Observing the phenomenal device, I conclude two important rules in order to achieve a perfect energy transfer at pounding. First, the point contact is accomplished by employing round-end touch; secondly, the perfect straight collision path is accomplished by a very careful alignment.

i) Vol. 44, No. 3, June 2004, pp. 103-114. (Previous discussion by C. R. Daniel and J. A. Howie, Vol. 45, No. 5, October 2005, pp. 121-126).

ii) Professor, Department of Civil Engineering, National Cheng Kung University, Tainan, 70701, Taiwan, R.O.C. (jstsai@mail.ncku.edu.tw). 


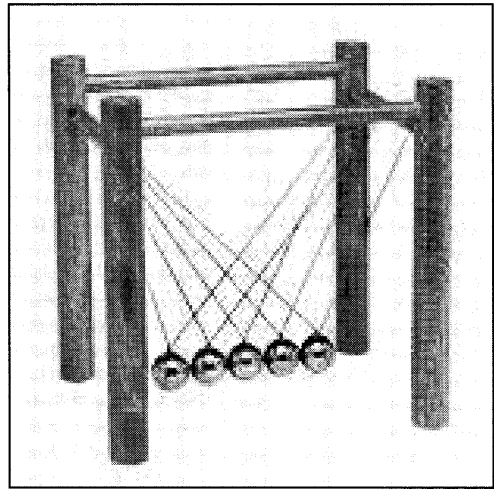

Fig. 21. Newton's cradle

Implementing the first rule derived from the Newton's cradle model, a round-top cap generates a point-impact and eases the possible distraction at pounding. This makes the anvil between the hammer and the rod more of an additional mass than an interface impedance. In the 1-D wave transmission model the anvil is represented as a lump mass other than a damper-spring. A simple Laplace Transform approach is applicable for predicting the force at any point on the rods given the force history at the top of the rods. On the other hand, the discussants' model assumes a plane-impact at pounding. This model inevitably introduces an unsure variable of the interface impedance and leaves the analytical results in doubt.

Implementing the second rule, all the laboratory tests conducted were carefully controlled to fulfill the 1-D condition. It turns out that the test results show nearly perfect impact. It is worth noting that a slight sway of the hammer-rod alignment would not noticeably alter the desired point-impact in a plane-to-point collision, while the plane-impact will be seriously affected once a planeto-plane colliding subjected to the same hammer's sway (Fig. 22). This explains why the energy loss in the anvil remains unresolved if a flat-top anvil is employed. This also provides explanation why the measured results only have little energy loss and the prediction of simple Laplace Transform analysis is in good accuracy.

It should be mentioned that the test set remains nearly unchanged, except for the hammer shifts, throughout the entire course of the test program. The possible system errors, though insignificant, should have appeared in all measurements. It is also noted that all the laboratory data apply so far only to the cases similar to our specific setup. Those data indicate that under perfect collision the effect of hammer shape to the energy measurement is insignificant. In field practices, the free-fall conditions are only met with modern automatic hammers, while donut hammers having guide rods and anvils of varying shapes and sizes are no doubt subjected to significant energy loss, especially for flat-top anvils of large size.

In our case, the $F^{2}$ method and the $F V$ method are equally good, and the velocity measurement is then optional.
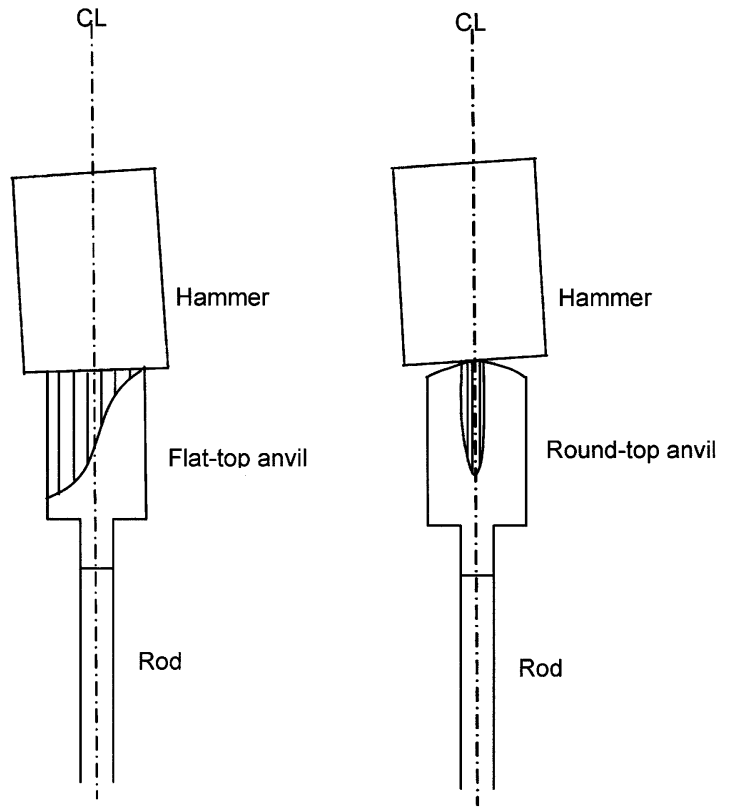

Fig. 22. Plane-to-plane vs. plane-to-point collision of slightly sway strike (Chen, 1999)

\section{WHAT IS THE PROBLEM IN REAL PRACTICES?}

I appreciate the contribution of the $F V$ method on solving the problem of the sectional change induced stress wave reflections. I however found that the $F V$ approach creates new challenges in our local practices. Some technical problems are encountered as a special sensor (load cell with accelerometers) is required to record the velocity. In short, there are manufacture problem, calibration problem, and the maintenance problem particularly resulted from the hot humid subtropical weather here.

Unlike the load cell required for the $F V$ method, the $F^{2}$ load cell is not hampered by the three problems mentioned above. For instance, the adopted $\boldsymbol{F}^{2}$ load cell is manufactured by students with limited technical training in our laboratory. The student-made load cell is calibrated using a conventional loading frame with ease. And dozens of calibrated load cells are readily available as backups whenever experiments, especially in field, are conducted, in which the $\boldsymbol{F}^{2}$ load cell is expendable and no maintenance is needed. It is worthy noted that I once had a valuable $F V$ load cell provided by an American friend in courtesy. It was so fragile that it barely survived the first pounding. Careless delivery and humid weather were the top suspects for the malfunctioning of its mounted accelerometers (for velocity measurements). At this point, I agree with the discussants upon the application of the $F V$ method is technically challenging relative to the $F^{2}$ method.

ASTM D4633-86 has been suspended for years with no corresponding substitute. The open status quo makes neither the $F V$ method the correct and currently accepted standard nor the $F^{2}$ method an outdated and unreliable one as the discussants perceived. To a certain extent, the 
unsure velocity determination from acceleration measurements remains an unresolved problem that holds the $F V$ method back from common acceptance. In a nutshell, creative studies on fixing mitigable drawbacks are equally important for the two methods since the test in practices is not whether the method is "scientifically" better, but whether it works better.

\section{References}

33) Chen, K. L. (1999): The study of standard penetration test energy measurement, Thesis of Master of Science presented to National
Cheng Kung University, Tainan, Taiwan, R.O.C. (in Chinese).

34) Farrar, J. A. (1998): Summary of standard penetration test (SPT) energy measurement experience, geotechncial site characterization, Proc. Ist Int. Conf. Site Characterization-ISC98- (eds. by Robertson and Mayne), Atlanta, GA, April 19-22, 1998, AA Balkema, Rotterdam.

35) Goldsmith, W. (1959): Impact: The Theory and Physical Behavior of Colliding Solids, Edward Arnold, London, U.K. (reprinted in 1998 by Dover Publications, Galveston, TX, U.S.A.)

36) Tsai, J. S. and Liou, Y. J. (2001): Effect of anvil shape on energy transfer measurement in standard penetration test, Proc. 9th Conf. Current Researches in Geotechnical Engineering, Shihman, Taiwan, R.O.C. A14-1-A14-7 (in Chinese). 